\title{
Practice and Reflection on Online Learning of Middle School Students Under the Situation of COVID-19 Pandemic and Lockdown: Taking Higher Vocational Colleges as An Example
}

\author{
Roshni Maloo ${ }^{1}$, Hasnain Ahmed ${ }^{2}$, Swetha $\mathrm{HB}^{3}$, Geeta $\mathrm{IB}^{4}$ \\ ${ }^{1}$ III BDS UG (undergraduate), Rajarajeshwari Dental College and Hospital, Ramohalli Cross, Kumbalgodu, Bengaluru, Karnataka, India \\ roshni.maloo@gmail.com
}

${ }^{2}$ III BDS UG (undergraduate), Rajarajeshwari Dental College and Hospital. Ramohalli Cross, Kumbalgodu, Bengaluru, Karnataka, India hasnainahmed017@gmail.com

${ }^{3}$ BDS, MDS, Professor, Department of Conservative and Endodontics, Rajarajeshwari Dental College and Hospital, Ramohalli Cross, Kumbalgodu, Bengaluru, Karnataka, India swethabalaraj@gmail.com

${ }^{4}$ BDS, MDS, HOD, Department of Conservative and Endodontics, Rajarajeshwari Dental College and Hospital, Ramohalli Cross, Kumbalgodu, Bengaluru, Karnataka, India geetasanjeev@gmail.com

\begin{abstract}
COVID-19 pandemic induced lockdown began all around the world by the month of March in 2020. As all the big economies of the world came to a standstill, education also took a setback. With all the schools and colleges being shut around the world, the students as well as the teachers had to adapt to a different method of learning that is in the form of online class, which were conducted using various online platforms. We constituted a survey by using Google forms and referring various scientific articles, and journals to assess the satisfaction and difficulties faced by the dental students in the pandemic. This survey was circulated among 400 students. In our survey we highlight the difficulties and setbacks which were faced by dental students exclusively in terms of theory and practical classes. Even though various new methods were adapted for the continuity of education some of which have had a positive impact but most of the participants felt that their clinical training was severely affected and felt unsatisfied with the online classes.
\end{abstract}

Keywords: COVID-19, Lockdown, Online Education, Academics, Clinical Experience

\section{Introduction}

Coronaviruses constitute the subfamily Orthocoronavirinae, in the family Coronaviridae, order Nidovirales, and realm Riboviria They are enveloped viruses with a positive-sense single-stranded RNA genome and a nucleocapsid of helical symmetry. The genome size of coronaviruses ranges from approximately 26 to 32 kilobases, one of the largest among RNA viruses. They have characteristic club-shaped spikes that project from their surface, which in électron micrographes create an image reminiscent of the solar corona, from which their name derives. [1]

Corona Virus disease 2019 (COVID-19) is caused by infection with the severe acute respiratory syndrome coronavirus 2 (SARS-CoV-2) virus strain. The first case of this infection was reported in Wuhan, China in the month of December 2019 [2] . It was then declared as a public health emergency of international significance and a global pandemic in January 2020 [3]. This infection is spread through direct, human-to-human contact (as caused by- coughing, sneezing, droplets of saliva expelled during the phonation) or indirect by contact with a contaminated surface and then touching the main body mucous membranes such as oral, ocular and nasal [4]. People with COVID 19 have a wide range of symptoms ranging from mild symptoms to severe illness. Symptoms may appear 2-
14 days after exposure to the virus. The most commonly seen symptoms are Fever, chills, cough, shortness of breath or difficulty in breathing, fatigue, muscle or body aches, headaches, loss of taste or smell, sore throat, nausea, vomiting, diarrhea. In severe conditions, when symptoms like trouble in breathing, persistent pain or pressure in the chest, confusion, inability to stay awake, pale, grey or blue colored skin lips or nail beds are seen immediate medical care is required [5].

The "SARS- CoV-2", counts, to date, high numbers of infected people. Globally, as of, 27 September 2021, there have been 231,703,120 confirmed cases of COVID-19, including 4,746,620 deaths, reported to WHO. As of 26 September 2021, a total of 5,924,819,985 vaccine doses have been administered [6]. In a recently published study, it was seen that, especially during the COVID-19 outbreak, dental practice can represent a high risk of spread of the disease. The aerosoles which are generated by dental procedures, are the smallest droplets suspended in the air, as well as the direct passage between patients and dentists can contribute to the spread of infection. The risk of transmitting the virus when performing dental procedures is extremely high due to the presence of droplets or aerosol particles of blood and salivary secretions. In addition, this aerosol production increases the contamination of dental equipment, dental chair, instruments and surfaces as this virus tends to be alive on different surfaces for a considerable period of 
time [7]

Healthcare education, specifically dental education is one of the most stressful higher education programs because of its complex and broad demands of didactic, patient management and technical clinical skills. Higher rates of depression and anxiety are prevalent among students. The above-mentioned factors may trigger symptoms such as anxiety, depression, emotional fatigue, and low academic achievement in dental students, resulting in early burn-out which is very commonly seen these days among students as well as practitioners [8].

\section{Literature Survey}

The corona virus pandemic has had devastating effects not only on health but also on the socioeconomic conditions of people in various countries [9].

The severity of the pandemic led all the big economies of the world come to a standstill education also took a setback. With all the schools and colleges being shut around the world, students and teachers had to adapt to a different method for continuing the student's education and clinical practices. One of the biggest challenges in regard to dental education has been to stop direct patient care which is an important part of the curriculum. Even though virtual sessions were conducted, none of those can duplicate or match the type of clinical experience received by the students in the clinics. e-learning proved to be a successful format in most of the streams, but this cannot be applicable in disciplines where patient care in the primary goal, students need to attend clinics to acquire the required knowledge and skill and to fulfill the requirements of their curriculum [10].

For conducting the online classes smoothly, teaching faculties had to learn and develop skills for online form of education which had been difficult for a few. Students have missed out on many valuable opportunities and clinical experience during this time [11].

The pandemic has also had immense psychological pressure on many students in a different way, which would have led to anxiety and depression among a few. Preclinical and clinical training is the most important part for the students, during this stage various manual and cognitive skills are acquired which prepare the students to enter the dental profession [10]. In our study we aim to highlight the challenges and the difficulties that were faced by the students during the pandemic. The other objective of this study was also to determine and analyze the satisfaction of the students in respect to online practical demonstrations, and we also highlight any difficulties which were faced by the students in attending online classes on time.

\section{Methods and Approach}

\subsection{Data collection}

A cross sectional survey was created using Google forms. For this survey a questionnaire was prepared referring various scientific articles, journals and surveys. The survey was made up of 17 questions which were arranged in a sequential order for the better understanding of the participants. The study was reviewed and approved by the institutional ethical committee. This survey was circulated among the students in the month of June 2021 using various social platforms. The authors received a total of 400 responses all of the responses were considered for this article. Statistical analysis for the sample was done using chi square goodness of fit test. To maintain the anonymity of the students any personal questions including their name, email address was kept optional. The survey included $72 \%$ females $(n=288)$ and $28 \%$ males $(n=112)$. The responses were then subdivided into various categories which are further discussed in the results and discussion portion of the article.

\section{Results and Discussions}

The total number of participants included in the study is 400 , this survey was circulated among the target audience of dental students in the month of June 2021 through various social platforms, the authors received a total of 400 completely filled forms all of which were used in the tabulation of the results of this survey. The results were further subdivided into various categories for easier understanding. The statistical analysis was done using chi square fitness for good test.

Section 1: Demographic Details:

To maintain the anonymity of the participants this section including the participants personal details i.e.; name, email address, etc. was kept optional.

\begin{tabular}{|c|c|c|c|}
\hline \multicolumn{4}{|c|}{ Age wise distribution of study participants } \\
\hline Variable & Category & $\mathrm{n}$ & $\%$ \\
\hline \multirow{4}{*}{ Age } & $<20$ yrs & 132 & $33.0 \%$ \\
\cline { 2 - 4 } & $21-25$ yrs & 259 & $64.8 \%$ \\
\cline { 2 - 4 } & $26-30$ yrs & 9 & $2.3 \%$ \\
\cline { 2 - 4 } & & Mean & SD \\
\cline { 2 - 4 } & Mean & 21.10 & 1.78 \\
\cline { 2 - 4 } & Range & \multicolumn{2}{|c|}{$17-30$} \\
\hline
\end{tabular}

Age wise distribution of study participants

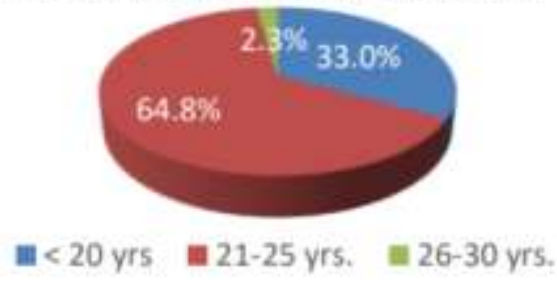

Figure 1.1: Age wise distribution of study participants

Table 1.1

Table 1.1 and Figure 1.1: Age wise distribution of the participants included in the study. The survey included $64.8 \%(n=259)$ participants between the age groups 21-25 years of age, $33.0 \%(\mathrm{n}=132)$ participants $<20$ years of and $2.3 \%(n=9)$ participants between the ages 26-30 years of age. The mean was found to be 21.10 and SD (sample standard deviation) 1.78 and the range 17-30. 


\begin{tabular}{|c|c|c|c|}
\hline \multicolumn{4}{|c|}{ Gender wise distribution of study participants } \\
\hline Variable & Category & $\mathrm{n}$ & $\%$ \\
\hline \multirow{2}{*}{ Gender } & Males & 112 & $28 \%$ \\
\cline { 2 - 4 } & Females & 288 & $72 \%$ \\
\hline
\end{tabular}

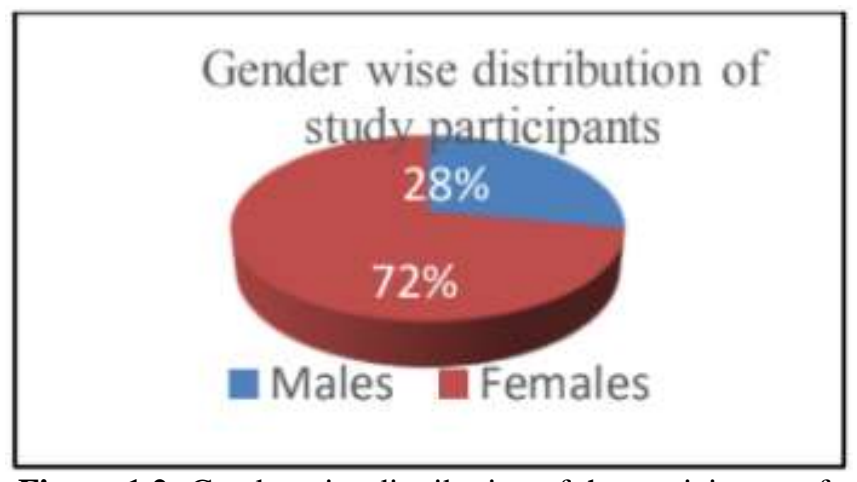

Figure 1.2: Gender wise distribution of the participants of the study

\section{Table 1.2}

Table 1.2 and Figure 1.2: Gender wise distribution of the participants of the study. The majority of the responses received were from female students $72 \%(\mathrm{n}=288)$ and the remaining $28 \%(n=112)$ were from male students.

\begin{tabular}{|c|c|c|c|}
\hline \multicolumn{4}{|c|}{ Distribution of study participants based on year of study } \\
\hline Variable & Category & $\mathrm{n}$ & $\%$ \\
\hline \multirow{4}{*}{$\begin{array}{c}\text { Year of } \\
\text { study. }\end{array}$} & I BDS & 60 & $15.0 \%$ \\
\cline { 2 - 4 } & II BDS & 98 & $24.5 \%$ \\
\cline { 2 - 4 } & III BDS & 117 & $29.3 \%$ \\
\cline { 2 - 4 } & IV BDS & 96 & $24.0 \%$ \\
\cline { 2 - 4 } & Interns & 19 & $4.8 \%$ \\
\cline { 2 - 4 } & PG Students & 10 & $2.5 \%$ \\
\hline
\end{tabular}

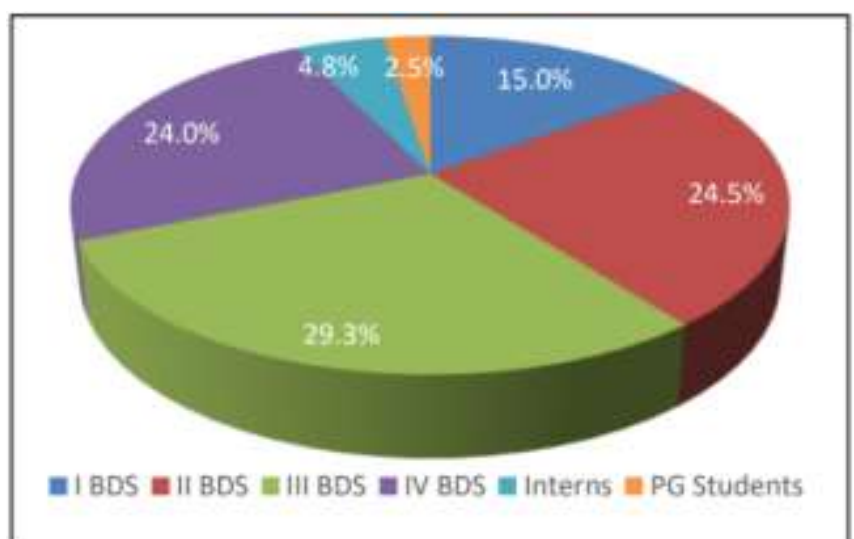

Figure 1.3: Distribution of participants based on the year of study

\section{Table: 1.3}

Table 1.3 and Figure 1.3: Distribution of participants based on the year of study. Students from various years were a part of this study including a total of $15.0 \%(\mathrm{n}=60)$ participants from $1^{\text {st }}$ BDS, $24.5 \%(n=98)$ from $2^{\text {nd }}$ BDS, $29.3 \%(n=117)$ from $3^{\text {rd }}$ BDS, $24.0 \%(n=96)$ from $4^{\text {th }}$ BDS, $4.8 \%(n=19)$ interns and $2.5 \%(n=10)$ post graduate students.

\section{Section 2}

Table 2.1: Comparison of distribution of responses for the questions on satisfaction \& access to online classes using

Chi Square Goodness of Fit Test

\begin{tabular}{|c|c|c|c|c|c|}
\hline Questions & Responses & $\mathrm{n}$ & $\%$ & $\chi^{2}$ Value & P-Value \\
\hline \multirow{2}{*}{$\begin{array}{c}\text { 1. Are you } \\
\text { satisfied with the } \\
\text { online form of } \\
\text { lectures (Theory)? }\end{array}$} & Yes & 183 & $45.8 \%$ & \multirow[b]{2}{*}{2.890} & \multirow[b]{2}{*}{0.09} \\
\hline & No & 217 & $54.3 \%$ & & \\
\hline \multirow{2}{*}{$\begin{array}{l}\text { 2. Are you } \\
\text { satisfied with the } \\
\text { online form of } \\
\text { clinical/ } \\
\text { preclinical } \\
\text { demonstrations } \\
\text { (practical)? }\end{array}$} & Yes & 58 & $14.5 \%$ & \multirow[b]{2}{*}{201.640} & \multirow[b]{2}{*}{$<0.001 *$} \\
\hline & No & 342 & $85.5 \%$ & & \\
\hline \multirow{2}{*}{$\begin{array}{l}\text { 3. Were you able } \\
\text { to access all the } \\
\text { scheduled online } \\
\text { classes on time? }\end{array}$} & Yes & 255 & $63.7 \%$ & \multirow[b]{2}{*}{30.250} & \multirow[b]{2}{*}{$<0.001 *$} \\
\hline & No & 145 & $36.3 \%$ & & \\
\hline
\end{tabular}

Table 2.1: Comparison of distribution of responses regarding the questions on satisfaction and access to online classes:

Majority of the participants of the survey $54.3 \%$ were not satisfies with the online form of lectures (theory classes) ( $p$ value $=0.09)$. In regards to the online clinical / pre-clinical demonstrations majority of the students $85.5 \%$ were not satisfied with the online method and felt that it was not much effective. Regarding the accessibility of the scheduled classes most of the students $63.7 \%$ were able to access all the scheduled classes without any difficulties ( $\mathrm{p}$ value $=$ $<0.001)$

Table 2.2: Comparison of distribution of responses for the questions on Self-confidence in clinical management of patients using Chi Square Goodness of Fit Test

\begin{tabular}{|c|c|c|c|c|c|}
\hline Questions & Responses & $\mathrm{n}$ & $\%$ & $\chi^{2 \text { Value }}$ & P-Value \\
\hline \multirow{3}{*}{ 4. Do you feel confident enough with the online form of learning? } & Yes & 52 & $13.0 \%$ & \multirow{3}{*}{108.980} & \multirow{3}{*}{$<0.001 *$} \\
\hline & No & 222 & $55.5 \%$ & & \\
\hline & Maybe & 126 & $31.5 \%$ & & \\
\hline \multirow{3}{*}{$\begin{array}{l}\text { 5. Do you feel the online clinical discussions and demonstrations will help } \\
\text { you in examinations or while setting up your clinic? }\end{array}$} & Yes & 37 & $9.3 \%$ & \multirow{3}{*}{201.605} & \multirow{3}{*}{$<0.001 *$} \\
\hline & No & 262 & $65.5 \%$ & & \\
\hline & Maybe & 101 & $25.3 \%$ & & \\
\hline 6. Do you feel satisfied with the type of clinical exposure received during the & Yes & 35 & $8.8 \%$ & 315.875 & $<0.001^{*}$ \\
\hline
\end{tabular}




\begin{tabular}{|c|c|c|c|c|c|}
\hline \multirow[t]{2}{*}{ pandemic? } & No & 300 & $75.0 \%$ & & \\
\hline & Maybe & 65 & $16.3 \%$ & & \\
\hline \multirow{3}{*}{$\begin{array}{l}\text { 7. Do you feel confident in managing the patients' requirements, based on } \\
\text { online learning? }\end{array}$} & Yes & 31 & $7.8 \%$ & \multirow{3}{*}{243.395} & \multirow{3}{*}{$<0.001 *$} \\
\hline & No & 276 & $69.0 \%$ & & \\
\hline & Maybe & 93 & $23.3 \%$ & & \\
\hline
\end{tabular}

Table 2.2: Comparison of distribution of responses for the questions in respect to the self confidence in students in the clinical management of patients. While assessing the confidence among the students with regard to the online classes most of the participants $55.5 \%(n=222)$ did not feel confident with the online form of classes which were conducted. $65.5 \%(n=262)$ of the participants did not feel confident enough in attending examinations and setting up their clinics with only the online mode of clinical discussions and demonstrations ( $\mathrm{p}$ value $=<0.001$ ), while $25.3 \%(n=101)$ participants suggested that they were mostly prepared to handle such situations. In respect to the type of clinical exposure received and confidence in patient management based on online learning majority of the participants felt under prepared as seen in table 2.2.

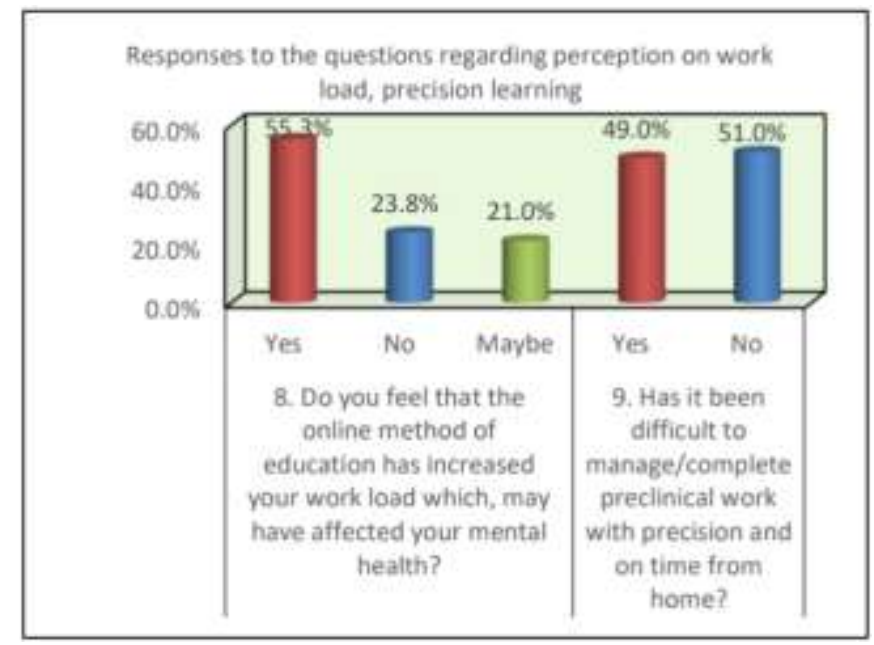

Graph 2.3:

Graph 2.3: Responses of the questions regarding perception on work load, precision learning:

Based on the questions which were asked to assess the mental health of the students $55.3 \%$ of the students reported that the online method of education affected their mental health. Most of the students $51.0 \%$ did not feel any difficulty in managing and completing the preclinical work with precision and on time. Whereas, a considerable number of participants $(49 \%)$ found completing any preclinical work at home to be slightly difficult due to various reasons.

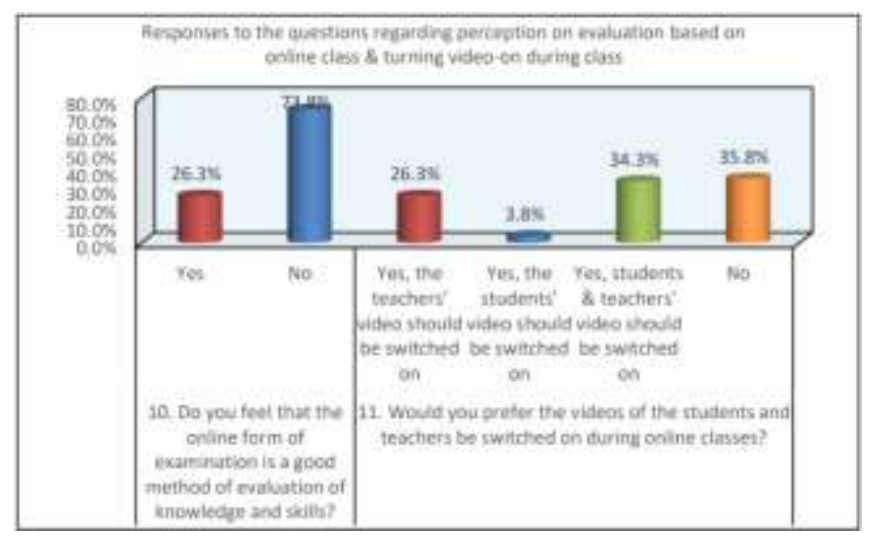

Graph 2.4

Graph 2.4: Responses to the questions regarding perception on evaluation based on online class and keeping the cameras switched on during class:

A question which was asked in regard to evaluation of the students' skill and knowledge based on online examination most of the participants $(73.8 \%)$ feel that online evaluation of one's skill and knowledge is not an adequate method of evaluation. Whereas, the question regarding whether the cameras be kept switched on during the duration of classes $(35.8 \%)$ students felt that keeping the videos switched in was not required, $34.3 \%$ of the participants felt that both the teachers and the student's cameras be switched on during the duration of the class as seen above in the graph 2.4.

Table 2.5: Comparison of distribution of responses for the questions regarding perception on effectiveness of vaccination \& offline classes during post lockdown using Chi Square Goodness of Fit Test

\begin{tabular}{|c|c|c|c|c|c|}
\hline Questions & Responses & $\mathrm{n}$ & $\%$ & $\chi^{2}$ Value & P-Value \\
\hline \multirow{2}{*}{$\begin{array}{l}\text { 12. After being vaccinated, would you feel comfortable and confident in } \\
\text { treating a patient with COVID-19 like symptoms? }\end{array}$} & Yes & 228 & $57.0 \%$ & \multirow{2}{*}{7.840} & \multirow{2}{*}{$0.005^{*}$} \\
\hline & No & 172 & $43.0 \%$ & & \\
\hline \multirow{3}{*}{$\begin{array}{l}\text { 13. How confident do you feel about the effectiveness of the vaccine in } \\
\text { returning to work/college? }\end{array}$} & Confident & 126 & $31.5 \%$ & \multirow{3}{*}{62.045} & \multirow{3}{*}{$<0.001 *$} \\
\hline & Not Confident & 73 & $18.3 \%$ & & \\
\hline & Not sure & 201 & $50.2 \%$ & & \\
\hline \multirow{3}{*}{$\begin{array}{l}\text { 14. How confident do you feel in attending the offline classes post } \\
\text { lockdown? }\end{array}$} & Very Confident & 148 & $37.0 \%$ & \multirow{3}{*}{5.360} & \multirow{3}{*}{0.07} \\
\hline & Not Confident & 112 & $28.0 \%$ & & \\
\hline & Not sure & 140 & $35.0 \%$ & & \\
\hline
\end{tabular}

Table 2.5: Comparison of responses for the questions regarding perception on effectiveness of vaccination and offline classes during post lockdown:

Most of the participants $57.8 \%(n=228)$ felt comfortable and confident in treating patients with COVID-19 like symptoms after being vaccinated. The questions regarding the confidence of the participants in the effectiveness of the vaccine in returning to work/college most of the participants $50.2 \% \quad(\mathrm{n}=201)$ were not sure about returning to 
college/work, $31.5 \%(\mathrm{n}=126)$ participants felt confident in the effectiveness of vaccine in returning to work/college. In regard to attending offline classes post lockdowns $37 \%$ $(\mathrm{n}=148)$ participants felt confident in returning to offline classes.

Table 2.6: Comparison of distribution of responses for the questions regarding perception on most effective vaccine \& most contagious variant of corona virus using Chi Square Goodness of Fit Test

\begin{tabular}{|c|c|c|c|c|c|}
\hline Questions & Responses & $\mathrm{n}$ & $\%$ & $X^{2}$ Value & P-Value \\
\hline \multirow{3}{*}{$\begin{array}{l}15 . \text { Which vaccine do you think is more } \\
\text { effective (according to your point of view)? }\end{array}$} & COVISHIEL D & 258 & $64.5 \%$ & \multirow[t]{3}{*}{174.845} & \multirow[t]{3}{*}{$<0.001 *$} \\
\hline & COVAXIN & 71 & $17.8 \%$ & & \\
\hline & Sputnik V & 71 & $17.8 \%$ & & \\
\hline \multirow{6}{*}{$\begin{array}{l}\text { 16. Which variant of Corona virus is the most } \\
\text { contagious? }\end{array}$} & Alpha & 7 & $1.8 \%$ & \multirow[t]{6}{*}{614.120} & \multirow[t]{6}{*}{$<0.001 *$} \\
\hline & Beta & 17 & $4.3 \%$ & & \\
\hline & Gamma & 16 & $4.0 \%$ & & \\
\hline & Delta & 219 & $54.8 \%$ & & \\
\hline & Delta Plus & 3 & $0.8 \%$ & & \\
\hline & Not sure & 138 & $34.5 \%$ & & \\
\hline
\end{tabular}

Table 2.6: Comparison of distribution of responses for the questions regarding perception on most effective vaccine and most contagious variant of corona virus:

$64.5 \%(n=258)$ participants suggested that covishield might be the most effective vaccine based on their point of view. The effectiveness of the vaccines is being determined by various studies and it is yet to be determined which vaccine might be the most effective one. Many vaccines have been manufactured and have been approved for use by various authorities around the world all of which have shown promising results. The question regarding the most contagious variant of the Coronavirus majority of the participants $54.8 \%(n=219)$ believe that the delta variant is the most contagious variant.

When the participants were asked on their suggestion on how would they as dental professionals play a role in handling the pandemic some of the suggestions were as follows:

"Educate patients to maintain good oral hygiene practice and take diet counselling so as to minimize poor oral health. Treat emergency patients and help them keep up their health."

"By keeping the infection control protocols in check while treating patients. And mostly by educating them how important it is to mask up and follow the preventive measures for controlling the spread of the virus."

"Dental students if supported and trained foe a week about essential treatment needs, then dental students are no less than medical students during the pandemic we are well equipped with the knowledge and skills to contribute to the nation just like any other doctor."

"Educating the people around you is the best way to start, and the dentist must be educated enough to diagnose the problem after seeing the oral manifestations of the patients."

While navigating the challenges bought upon by the pandemic induced lockdowns and a shift in the normal method of teaching and practice, faculty members successfully navigated through training to use the online platforms for the continuity of the education. Still not everyone had the same level of technological expertise. The necessary infrastructure and materials were also not available to the students as well as the teachers to aid in demonstrations and practicing their preclinical skills.

While there have been some positive effects regarding online education this study definitely highlights the challenges and the difficulties faced by the students during this time. Most of the participants suggested that they were hesitant in their skills and would like more practice with time. The most negatively affected part of the student's academics were their pre-clinical courses which form the basis for any procedures which are carried out in the future by the students in the treatment of the patients which is a major part of the curriculum. Many of the participants also agree that online method of examinations is not a good method of evaluation of their skill and knowledge.

\section{Future Scope}

Further studies on this topic can be conducted comparing the positive and negative impact of the pandemic on students by using a bigger sample size. Due to time constraints and limitation of resources this study included only a small group of students from Bangalore and Chennai but further studies can include more participants from other pats of the country as well.

\section{Conclusion}

Online method of education has been a new experience for both the teachers as well as the students, some of the teachers were able to adapt quickly with this method of teaching whereas it proved to be a little challenging for some. From the student's perspective the e-lectures were well appreciated as well as the discussions forums. The negative impact on the students was definitely the lack of patient exposure as well as loss of the valuable practical sessions. Treating and management of patients forms a large portion of the curriculum and is a skill which is acquired through practice, most of the participants agreed that they were not able to receive full exposure and opportunities to fine tune those skills. Some students may also experience anxiety and depression which might be due to lack of sufficient training, and the fear of contracting COVID-19 
during their clinical posting [12].

\section{References}

[1] Cherry J, Demmler-Harrison GJ, Kaplan SL, Steinbach WJ, Hotez PJ (2017). Feigni and Cherry's Textbook of Pediatric Infectious Diseases. Elsevier Health Sciences.

[2] Trishnika Chakraborty, Gireesh Kumar Subbiah. Psychological distress during COVID-19 lockdown among dental students and practitioners in India: A cross-sectional survey.

[3] Kamis Gaballah. The emotional impact of the Coronavirus Disease 2019 (COVID-19) Pandemic on the dental students during lockdown time.

[4] Bruna Sinjari, Imena Rexhepi, Manilo Santilli, Gianmaria D'Addazio, Piero Chiacchiaretta, Piero Di Carlo, Sergio Caputi. The impact of COVID-19 Related lockdown on Dental Practice in Central Italy- Outcomes of a Survey.

[5] WWW.CDC.GOV.IN

[6] WHO coronavirus (COVID-19) Dashboard. https://covid19.who.int

[8] Zaki Hakami, Satish Vishwanathaiah, Samar Hatem Abuzinadah, Abdulrahman Jafar Alhaddad. Effects of COVID-19 lockdown on the mental health of students: A longitudinal study.

[9] Aiza Anwar, Hajra Mansoor and Huma Saeed Khan. Elearning amid the COVID-19 Lockdown: Standpoint of Medical and Dental Undergraduates. Pakistan Journal of Medical Sciences.

[10] Susan Hattar, Abeer AlHadidi, Faleh A Sawair, Islam Abd Alraheam, Ahmad El-Ma'aita, Fouad Kadim Wahab. Impact of COVID-19 pandemic on dental academia. Students experience for a predictable practice. 